\title{
Hybrid nanostructured aluminum alloy with super-high strength
}

\author{
Zhi Wang ${ }^{1,2}$, Rui T Qu ${ }^{3}$, Sergio Scudino', Bao A Sun${ }^{1}$, Konda G Prashanth ${ }^{1}$, Dmitri V Louzguine-Luzgin ${ }^{2}$, \\ Ming W Chen ${ }^{2}$, Zhe F Zhang ${ }^{3}$ and Jürgen Eckert ${ }^{4,5}$
}

Methods to strengthen aluminum alloys have been employed since the discovery of the age-hardening phenomenon in 1901. The upper strength limit of bulk Al alloys is $\sim 0.7 \mathrm{GPa}$ by conventional precipitation strengthening and increases to $>1 \mathrm{GPa}$ through grain refinement and amorphization. Here we report a bulk hybrid nanostructured Al alloy with high strength at both room temperature and elevated temperatures. In addition, based on high-resolution transmission electron microscopic observations and theoretical analysis, we attribute the strengthening mechanism to the composite effect of the high-strength nanocrystalline fcc-Al and nano-sized intermetallics as well as to the confinement effect between these nano phases. We also report the plastic deformation of nano-sized intermetallics and the occurrence of a high density of stacking faults and twins in fcc-Al after low-strain-rate deformation at room and high temperatures. Our findings may be beneficial for designing highstrength materials for advanced structural applications.

NPG Asia Materials (2015) 7, e229; doi:10.1038/am.2015.129; published online 4 December 2015

\section{INTRODUCTION}

Aluminum $(\mathrm{Al})$ is one of the most widely used nonferrous metals for structural applications owing to its positive combination of low density, high specific strength, high corrosion resistance, good machinability and excellent recyclability. ${ }^{1}$ Driven by the requirement to increase the low strength of pure $\mathrm{Al}$, efforts to develop highstrength $\mathrm{Al}$ alloys have been ongoing since Alfred Wilm discovered the age-hardening phenomenon in 1901.2,3 Over the past century, methods based on a variety of strengthening theories, including solid solution and precipitation strengthening, work hardening and grain boundary (GB) strengthening, have gradually been established. ${ }^{4}$ Application of these strengthening mechanisms has led to the development of a series of engineered $\mathrm{Al}$ alloys with improved strength. However, the yield strength level of these Al alloys is, in general, limited to $\sim 700 \mathrm{MPa}^{5}$

Recently, the development of high-strength $\mathrm{Al}$ alloys has been carried out through two main approaches: $:^{5-11}$ (1) the creation of ultra-fine-grained or nanocrystalline (NC) Al alloys that, owing to their refined microstructure, display very high strength along with appreciable plasticity, and (2) the production of Al-based metallic glasses (MGs) that are free of crystalline defects such as GBs or dislocations and thus have very high strength. Although these approaches are quite effective for the production of high-strength $\mathrm{Al}$ alloys, critical limitations still exist. For example, the achievable sizes of Al-based MGs are rather limited (generally $\leqslant 1 \mathrm{~mm}$ ) by the poor glassforming ability of Al-based alloys. ${ }^{12}$ In addition, the non-equilibrium state and the poor thermal stability of the NC or MG Al alloys limit their use at high temperatures. ${ }^{12,13}$ An alternative approach to preparing NC materials is to crystallize amorphous solids under appropriate heat treatment conditions. ${ }^{12,14-17}$ Although this provides a successful method to synthesize $\mathrm{Al}$ alloys with strengths approaching the maximum, it does not offer good control over the microstructure and resulting properties, which are essentially determined by the crystallization behavior of the amorphous precursors. Here we report a microstructural strategy for the production of Al-based alloys with super-high strength and elucidate the strengthening mechanisms.

\section{EXPERIMENTAL PROCEDURES}

Powders with nominal composition $\mathrm{Al}_{84} \mathrm{Ni}_{7} \mathrm{Gd}_{6} \mathrm{Co}_{3}$ (at.\%) were produced by the Ar gas atomization method. Milling experiments were carried out using a Retsch PM400 planetary ball mill (Retsch GmbH, Düsseldorf, Germany) under protective argon atmosphere (for additional details, see Wang et al. ${ }^{18}$ ). To avoid any possible contamination during the course of milling, powder charging and any subsequent sample handling were performed in a Braun MB 150B-G glove box (M.Braun GmbH, München, Germany) under purified argon atmosphere ( $<1$ p.p.m. of $\mathrm{O}_{2}$ and $\mathrm{H}_{2} \mathrm{O}$ ). The oxygen content analysis was performed via carrier gas-hot extraction using a LECO USA TC-436 DR analyzer (LECO Co. Ltd., St. Joseph, MI, USA). The iron content was evaluated using a CARL ZEISS Specord M500 Spectrophotometer (Carl Zeiss Jena GmbH, Jena, Germany). A series of $\mathrm{Al}_{84} \mathrm{Ni}_{7} \mathrm{Gd}_{6} \mathrm{Co}_{3}$ bulk cylinders (diameter $10 \mathrm{~mm}$ and length $\sim 10 \mathrm{~mm}$ ) were produced by hot pressing at $640 \mathrm{MPa}$ and $T_{\mathrm{hp}}=773 \mathrm{~K}$ using gas-atomized powders (HP0) and powders milled for $50 \mathrm{~h}$ (HP1) and $100 \mathrm{~h}$ (HP2). Approximately $2-3.5 \mathrm{~g}$ of powder was first placed in a die of $10 \mathrm{~mm}$

${ }^{1}$ IFW Dresden, Institut für Komplexe Materialien, Postfach, Germany; ${ }^{2}$ WPI Advanced Institute for Materials Research (WPI-AIMR), Tohoku University, Sendai, Japan; ${ }^{3}$ Shenyang National Laboratory for Materials Science, Institute of Metal Research, Chinese Academy of Sciences, Shenyang, China; ${ }^{4}$ Erich Schmid Institute of Materials Science, Austrian Academy of Sciences, Leoben, Austria and ${ }^{5}$ Department Materials Physics, Montanuniversität Leoben, Leoben, Austria

Correspondence: Dr Z Wang, WPI Advanced Institute for Materials Research (WPI-AIMR), Tohoku University, Sendai 980-8577, Japan.

E-mail: angw_zhi@sina.com or zhi.wang@wpi-aimr.tohoku.ac.jp

Received 19 June 2015; revised 9 September 2015; accepted 28 September 2015 
diameter and then preloaded to $20 \mathrm{kN}$. To minimize the risk of oxygen contamination, the chamber was evacuated to approximately $1 \times 10^{-4} \mathrm{~Pa}$ before hot pressing for degassing. Once the desired hot pressing temperature was reached, hot pressing was performed isothermally for $3 \mathrm{~min}$ of dwell time. After hot pressing, argon was purged to remove the samples from the chamber. Phases and microstructures were studied by X-ray diffraction using a Philips PW 1050 diffractometer (Philips, Eindhoven, The Netherlands) (Co K radiation), by scanning electronic microscopy (SEM) using a Leo Gemini 1530 microscope (Zeiss, Oberkochen, Germany) equipped with energydispersive X-ray (EDX) and by transmission electron microscopy (TEM) using a Philips Tecnai F30 microscope (FEI, Eindhoven, The Netherlands) operating at $300 \mathrm{kV}$ with an EDX and JEOL HRTEM 2100 (JEOL Ltd., Tokyo, Japan) with a field-emission gun. In accordance with the ASTM standard for compression testing, cylinders with a length/diameter ratio of $2.0(6 \mathrm{~mm}$ in length and $3 \mathrm{~mm}$ in diameter) were prepared from the consolidated samples. The specimens were tested at room temperature using an Instron 8562 testing facility (Instron Co., Norwood, MA, USA) under quasistatic loading (strain rate $\left.1 \times 10^{-3} \mathrm{~s}^{-1}\right)$ and at elevated temperatures using an Instron 8562-3 machine (strain rate of $1 \times 10^{-4} \mathrm{~s}^{-1}$ ), and at least three specimens were randomly selected and tested for each parameter. The microhardness measurements were carried out using an HMV Shimadzu Vickers hardness testing machine (Shimadzu Co. Ltd., Kyoto, Japan). The hardness values reported here are the averages of $>25$ indentations per sample. The Young's modulus was measured using a MATEC 6600 ultrasonic system (Matec Instrument Companies Inc., Northborough, MA, USA) on plane parallel samples with $\sim 10 \mathrm{~mm}$ diameter and $\sim 10 \mathrm{~mm}$ length. Nanoindentation was performed at room temperature using an Agilent NanoSuite Nanoindentation G200 (Agilent Technologies, Santa Clara, CA, USA) equipped with a Berkovich tip. A constant indentation strain rate $((\mathrm{d} P / \mathrm{d} t) / P)$ of $0.05 \mathrm{~s}^{-1}$ was used in the present study.

\section{RESULTS AND DISCUSSION}

The microstructural strategy for developing high-strength $\mathrm{Al}$ alloys was tested on the $\mathrm{Al}_{84} \mathrm{Ni}_{7} \mathrm{Gd}_{6} \mathrm{Co}_{3}$ alloy, which was selected because its component elements have negligible solubility in $\mathrm{Al}$; therefore, several intermetallics can be formed. ${ }^{18}$ Our processing strategy consists of three steps: gas atomization, ball milling, and hot pressing, as illustrated in Figure 1. Gas atomization is used to produce the amorphous particulate precursor (Figure 1a). The rapidly cooled small gas atomized particles are amorphous, whereas the slowly cooled large particles display minor amounts of fcc- $\mathrm{Al}$ and $\mathrm{Al}_{19} \mathrm{Gd}_{3} \mathrm{Ni}_{5}$ phases. ${ }^{18}$ The powders were then treated by ball milling, a severe plastic deformation process that we used in order to vary the microstructure and crystallization behavior of the amorphous precursor (Figure 1b). Finally, the powders were consolidated into highly dense bulk samples by hot pressing at a relatively high temperature, at which the combined devitrification and consolidation of the amorphous particulate precursor occurred (Figure 1c). Through this method, a series of $\mathrm{Al}_{84} \mathrm{Ni}_{7} \mathrm{Gd}_{6} \mathrm{Co}_{3}$ bulk specimens labeled HP0 (ball milling time, $t_{\mathrm{bm}}=0 \mathrm{~h}$ (that is, as-atomized); hot pressing temperature, $\left.T_{\mathrm{hp}}=773 \mathrm{~K}\right), \mathrm{HP} 1 \quad\left(t_{\mathrm{bm}}=50 \mathrm{~h} ; T_{\mathrm{hp}}=773 \mathrm{~K}\right), \quad \mathrm{HP} 2$ $\left(t_{\mathrm{bm}}=100 \mathrm{~h} ; T_{\mathrm{hp}}=773 \mathrm{~K}\right)$ and HP3 $\left(t_{\mathrm{bm}}=100 \mathrm{~h} ; T_{\mathrm{hp}}=673 \mathrm{~K}\right)$ were synthesized.

The milling step has a fundamental influence on the final microstructure of the consolidated samples. At the initial stage of milling, the small amorphous particles adhered to the surface of the larger crystalline particles (which remained relatively unaffected); with an increased milling time, they formed particles with a composite structure consisting of an irregular amorphous layer that completely covered the crystalline core (Figure 1b2). The microstructure of the bulk samples, which clearly resembled the composite structure of the parent milled powder (compare Figures $1 \mathrm{~b} 2$ and c2), consisted of regions with coarse precipitates surrounded by regions containing fine nanoscaled phases. The volume fraction of the fine precipitate regions in the consolidated samples increased with increasing milling time, from $\sim 0$ vol. $\%\left(t_{\mathrm{bm}}=0 \mathrm{~h}\right)$ to $\sim 64 \mathrm{vol} . \%\left(t_{\mathrm{bm}}=100 \mathrm{~h}\right)$; conversely, the volume fraction of the coarse precipitate regions decreased with milling time, as shown in Supplementary Figure S1a. The size distribution of the coarse precipitate regions in HP2 is shown in Supplementary Figure S1b, which has an average diameter of $\sim 17 \mu \mathrm{m}$. The size and volume fraction of the coarse precipitate region were estimated from the SEM images. No exothermic peak due to crystallization is evident in the differential scanning calorimetry curve of HP2 (compare Figures 1a4 and 1c4), which indicates that full devitrification was achieved in the consolidated bulk sample. The main requirement to obtain this unique structure is the negligible solid solubility of the components in $\mathrm{Al}$, which allows the formation of intermetallic phases, and the ball milling procedure can vary the volume fraction and size of the phases precipitated from the amorphous matrix. The content ratio between $\mathrm{Al}$ and the unsolvable elements will affect the final microstructure, including the volume fraction of the fcc-Al and intermetallic phases.

After the consolidation process, the samples exhibit low porosity and have a density in the range of $3.7-3.8 \mathrm{~g} \mathrm{~cm}^{-3}$. Figure 2 displays the typical microstructure feature of HP2. The bright area in the optical micrographic image shown in Figure 2a, which corresponds to the black inter-particle area in the SEM image in Figure 1c2, is pure fcc-Al phase rather than pores, according to the EDX analysis (see Supplementary Figure S2). Further TEM analysis (Figure 2b) shows that the submicron pores are also difficult to find in the inter-particle area. From Figure $2 c$, one can see that the boundary between particles is discontinuous, and a thin amorphous layer with a thickness $<5 \mathrm{~nm}$ can be seen. The amorphous GB phase is probably the surface oxidation layer of the particles. Based on chemical analysis, the oxygen content and iron content of the milled 100-h powder are approximately $0.69 \mathrm{wt} \%$ and $0.08 \mathrm{wt} \%$, respectively. The oxygen content in the milled powder is not low. Nevertheless, the amorphous oxide surface of the particle is broken down, which may occur both in the milling process owing to severe plastic deformation and in the subsequent consolidation process owing to high temperature and pressure.

A bimodal-like microstructure consisting of the regions with coarse and fine precipitates is shown in Figures $2 \mathrm{~d}-\mathrm{f}$. The enlarged SEM micrograph of the coarse precipitate region further confirms that the dark areas in the coarse and fine precipitate regions are the $\mathrm{Al}$ phase rather than pores (see Supplementary Information S3). Analysis of the microstructure shows that the volume fraction of the fine precipitate region (refer to Supplementary Information S4 for the detailed method of measuring the volume fraction) increases from 0 vol. \% for HP0 to $\sim 43, \sim 64$ and $\sim 100$ vol. \% for HP1, HP2 and HP3, respectively, which indicates that the temperature and pressure used in the consolidation process have a significant influence on the microstructure of the bulk alloys.

In addition to the bimodal structure of the coarse and fine precipitate regions at the microscale, at the nanoscale the material exhibits hybrid structures that consist of nanometric rod-like phases, equiaxed particle-like phases and matrix, as shown in Figure 3. A combination of X-ray diffraction analysis, EDX analysis and selected-area diffraction identifies the nanometric rod-like phases as $\mathrm{Al}_{19} \mathrm{Gd}_{3} \mathrm{Ni}_{5}$ intermetallic compounds; the equiaxed phases are mixtures of $\mathrm{Al}_{3} \mathrm{Gd}$ and $\mathrm{Al}_{9} \mathrm{Co}_{2}$, and the matrix is fcc-Al. In the fine precipitate regions, fcc- $\mathrm{Al}$ has a very fine grain size of $\sim 80 \mathrm{~nm}$, whereas the rod-like $\mathrm{Al}_{19} \mathrm{Gd}_{3} \mathrm{Ni}_{5}$ is $\sim 30 \mathrm{~nm}$ wide and $\sim 130 \mathrm{~nm}$ long, and the average size of the $\mathrm{Al}_{3} \mathrm{Gd}$ and $\mathrm{Al}_{9} \mathrm{Co}_{2}$ phases is $100-250 \mathrm{~nm}$. By contrast, the sizes of these phases in the coarse precipitate regions 

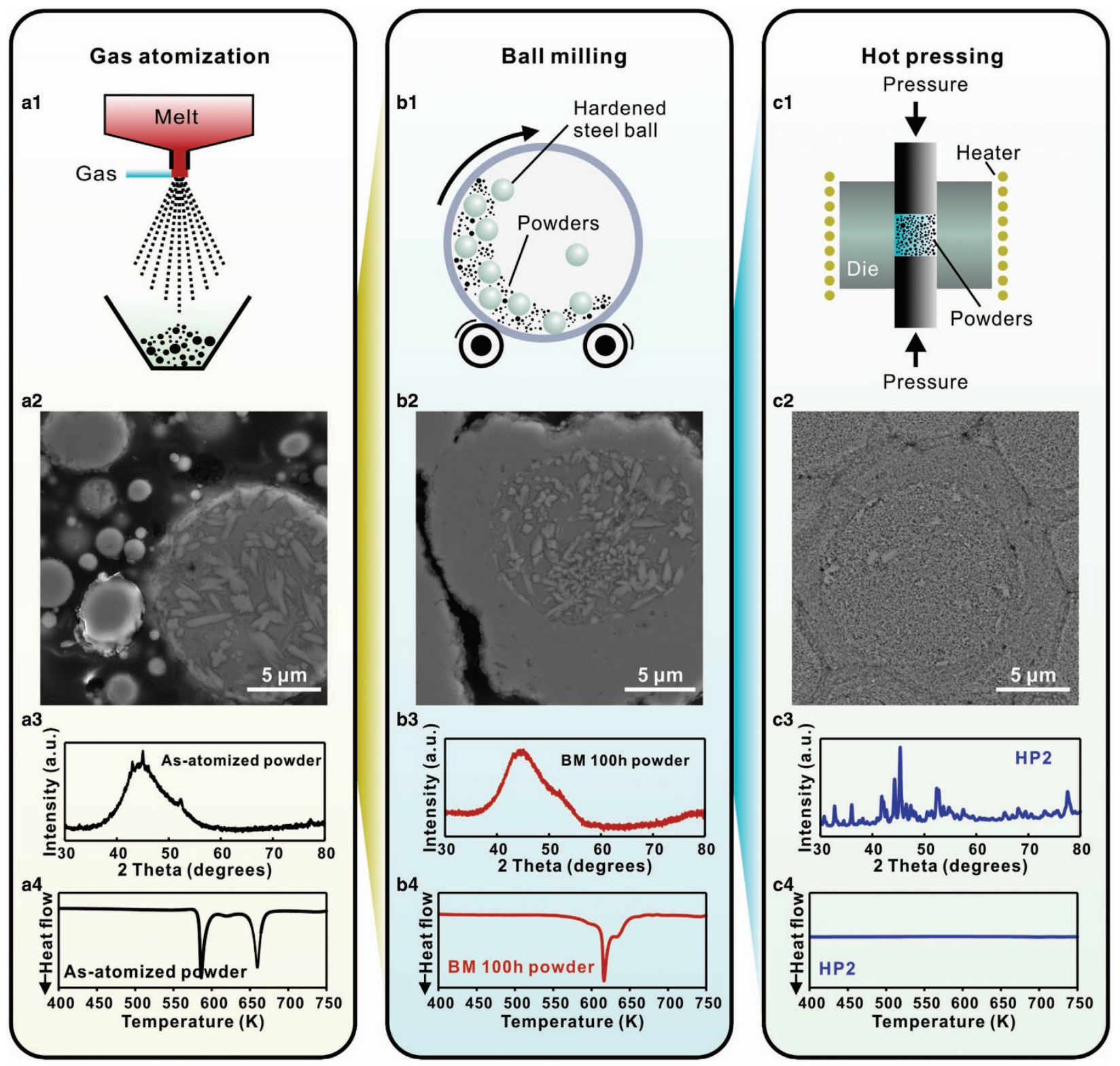

Figure 1 Processing of the $\mathrm{Al}_{84} \mathrm{Ni}_{7} \mathrm{Gd}_{6} \mathrm{CO}_{3}$ alloys: Gas atomization $(\mathbf{a}(1-4))$, ball milling $(\mathbf{b}(1-4))$ and hot pressing (c(1-4)). Schematic processing methods (a1, b1 and $\mathbf{c} 1$ ) and corresponding SEM backscattered electron (BSE) imaging (a2, b2 and c2), XRD (a3, b3 and c3) and differential scanning calorimetry (a4, b4 and c4) results of obtained microstructures. The powder in panel a2 was as-atomized. The powder in panel b2 was milled for $50 \mathrm{~h}$. The microstructure shown in panel c2 corresponds to sample HP1.

are slightly larger: the average grain size of fcc- $\mathrm{Al}$ is $\sim 90 \mathrm{~nm}$ and the length of the $\mathrm{Al}_{19} \mathrm{Gd}_{3} \mathrm{Ni}_{5}$ rods is $\sim 230 \mathrm{~nm}$ (see Supplementary Figure S4 and Table 1 for further details). The interfaces between these phases are continuous and well bonded, as demonstrated by the high-resolution TEM shown in Figure 3e.

\section{Mechanical properties}

Figure $4 \mathrm{a}$ shows typical compressive true stress-strain curves of the consolidated bulk samples at room temperature. Both the yield $(0.2 \%$ offset $)$ and ultimate strengths increase with increasing milling time from $\sim 0.93$ and $\sim 1.28 \mathrm{GPa}$ for HP0 $\left(t_{\mathrm{bm}}=0 \mathrm{~h}\right)$ to $\sim 1.37$ and $\sim 1.77 \mathrm{GPa}$ for HP2 $\left(t_{\mathrm{bm}}=100 \mathrm{~h}\right)$. The high strength is accompanied by a strain to fracture of $\sim 5 \%$. By controlling the consolidation temperature, the microstructure (for example, the volume fraction of the fine precipitate regions) can also be tuned. For example, HP3 with
$T_{\mathrm{hp}}=673 \mathrm{~K}$ exhibits a microstructure that consists of nearly $100 \%$ fraction of fine precipitate regions and hence has a high yield strength of $\sim 1.68 \mathrm{GPa}$. The high strength of the present $\mathrm{Al}$ alloys can also be retained at elevated temperatures. The compressive strength at $523 \mathrm{~K}$ increases from $0.91 \mathrm{GPa}$ for HP0 to $1.08 \mathrm{GPa}$ for HP2 (Figure 4b). At a higher testing temperature $(623 \mathrm{~K})$, the compressive strength of both alloys also maintains a high level of $0.45 \mathrm{GPa}$. The high strength at elevated temperatures indicates that the hybrid microstructure of the present alloys is more thermally stable than those of other nanostructured $\mathrm{Al}$ alloys. To the best of our knowledge, the present $\mathrm{Al}$ alloys exhibit the highest compressive strength at both room and high temperatures among all $\mathrm{Al}$ alloys reported to date, as summarized in Figure 4c.

In addition to the high strength, these alloys have a high Young's modulus $(E)$. For example, $E=119 \mathrm{GPa}$ for HP2, which is much 

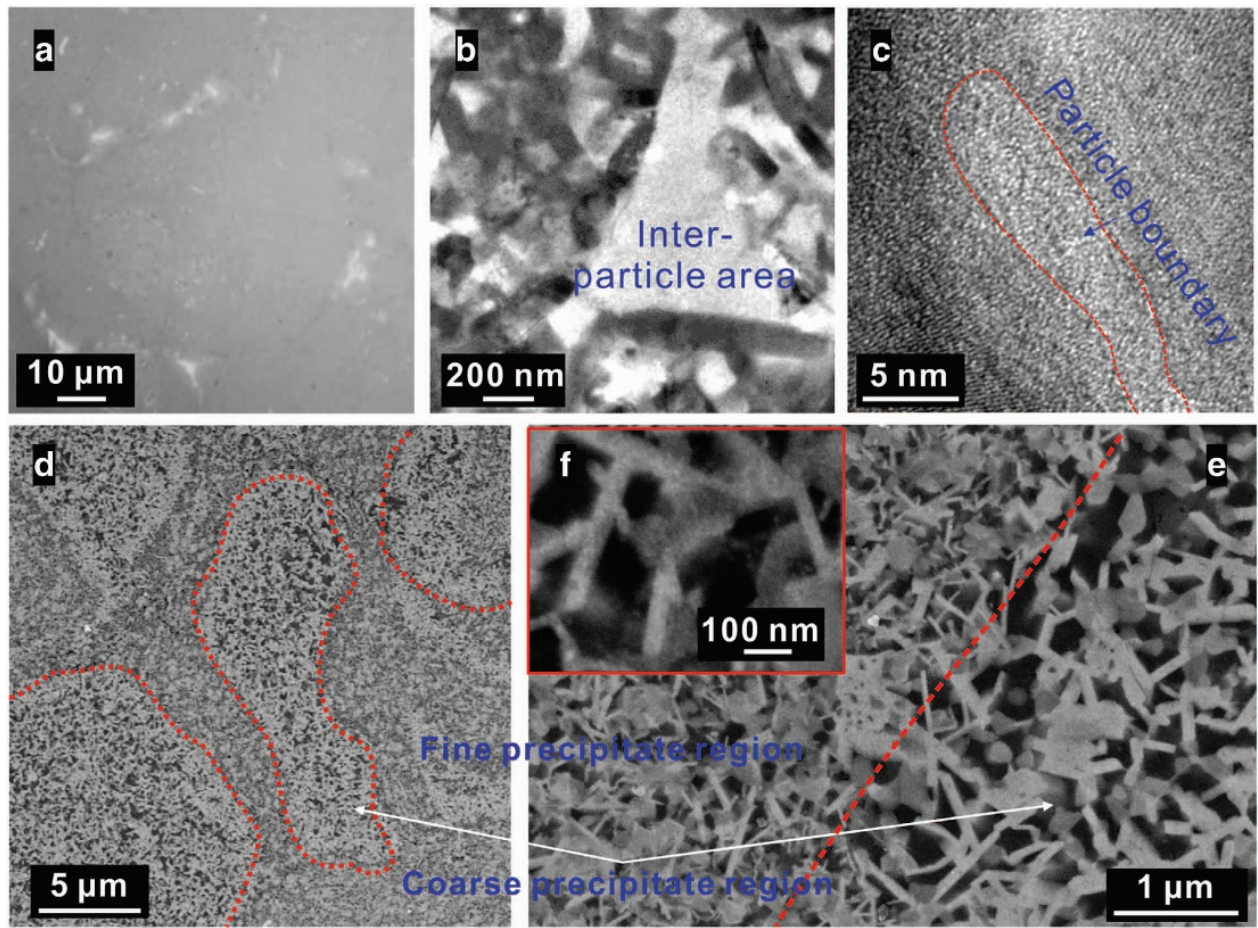

Figure 2 Microstructures of the hot-pressed $\mathrm{Al}_{84} \mathrm{Ni}_{7} \mathrm{Gd}_{6} \mathrm{CO}_{3}$ alloys. (a) Optical micrograph image of sample HP2 showing the inter-particle area. (b) Brightfield TEM image of triple inter-particle area. (c) High-resolution TEM image of interface between the consolidated particles. (d-f) SEM BSE images of sample HP2 showing fine and coarse precipitate regions.
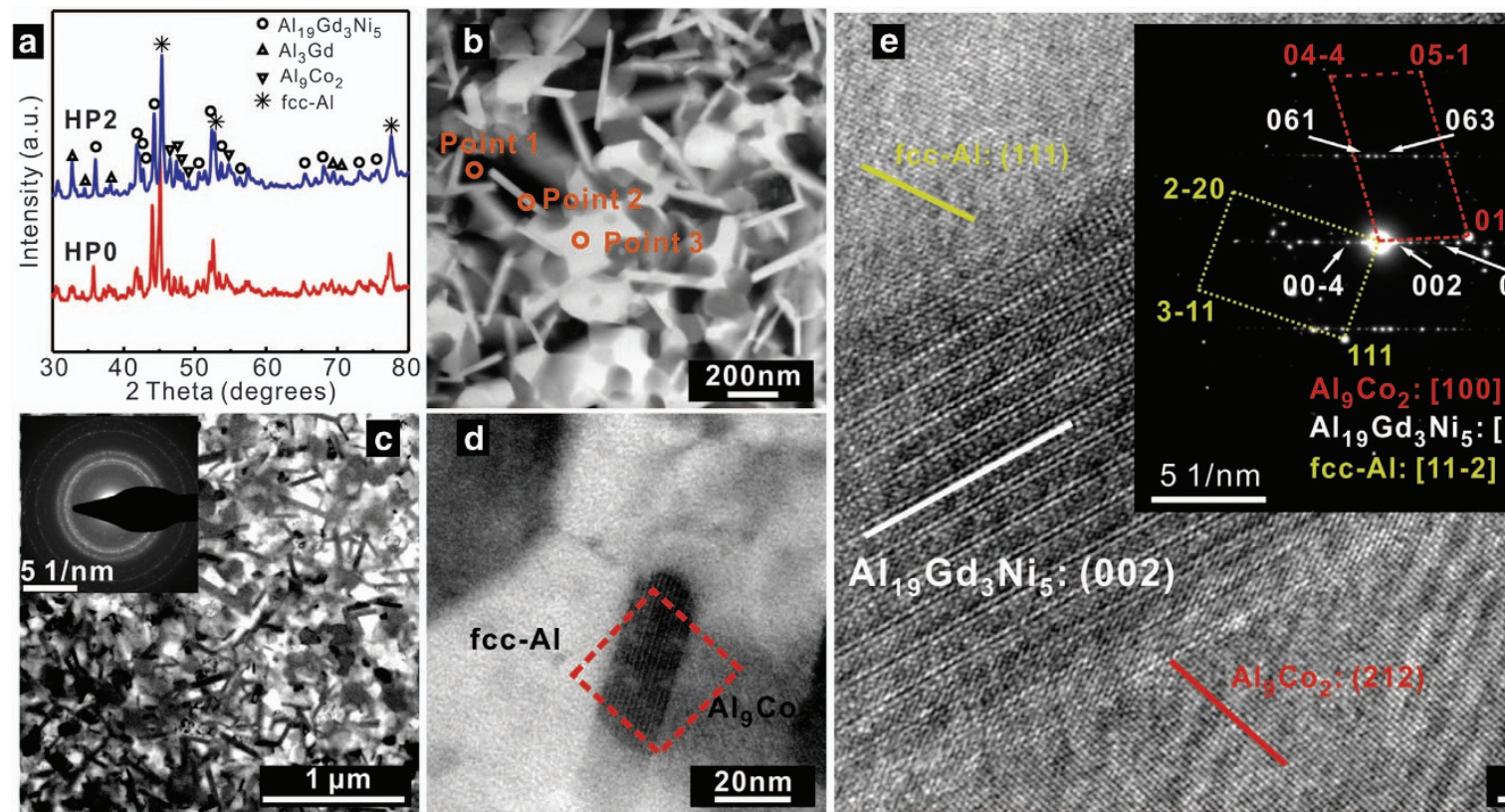

\section{$2-20$}
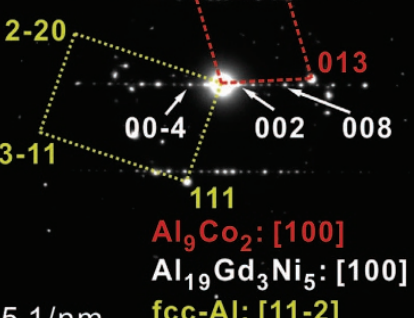

\section{$51 / \mathrm{nm} \quad$ fcc-Ä: [11-2]}

Figure 3 Microstructures and phases of the hot-pressed $\mathrm{Al}_{84} \mathrm{Ni}_{7} \mathrm{Gd}_{6} \mathrm{Co}_{3}$ alloys. (a) XRD patterns for HP2 and HPO, indicating a large volume fraction of intermetallic compounds. (b) STEM image of HP2 displaying a hybrid nanoscaled structure with NC fcc-Al and nanometric intermetallics. Points 1-3 were analyzed by EDX, and the results are listed in Supplementary Table S1. (c, d) Bright-field TEM of HP2. (e) High-resolution TEM (HRTEM) image of the rectangle area in panel (d), revealing well-bonded interfaces between NC fcc-Al and the intermetallic phases.

higher than the values for common Al alloys (typically $<80 \mathrm{GPa}$ ). ${ }^{19}$ Although the strength and Young's modulus are very high, the density of the present alloys is rather low $\left(\sim 3.75 \mathrm{~g} \mathrm{~cm}^{-3}\right)$ owing to high $\mathrm{Al}$ content. This leads to excellent specific properties of the present alloys; for example, the specific strength of HP2 is $496 \mathrm{kNm} \mathrm{kg}^{-1}$ and its specific Young's modulus is $32 \mathrm{MNm} \mathrm{kg}^{-1}$. By tuning the processing conditions, different $\mathrm{Al}$ alloys with adjustable microstructures and properties can be synthesized, which adds a new and promising region to the Ashby map of specific yield strength versus the specific Young's modulus, as shown in Figure $4 \mathrm{~d}$. 
Table 1 Volume fraction, nanohardness and Young's modulus of the phases in coarse and fine precipitate regions

\begin{tabular}{|c|c|c|c|}
\hline Phases & $\begin{array}{c}\text { Volume } \\
\text { fraction (\%) }\end{array}$ & $\begin{array}{c}\text { Nanohardness } \\
\text { (GPa) }\end{array}$ & $\begin{array}{c}\text { Young's modulus } \\
\text { (GPa) }\end{array}$ \\
\hline In fine precipitate region & & $7.0 \pm 0.5$ & $148.3 \pm 9.0$ \\
\hline fcc-Al & $21 \pm 3$ & $1.3 \pm 0.1$ & $74 \pm 6$ \\
\hline $\mathrm{Al}_{19} \mathrm{Gd}_{3} \mathrm{Ni}_{5}$ & $19.5 \pm 5$ & $5.9 \pm 0.5$ & $185 \pm 4$ \\
\hline $\mathrm{Al}_{9} \mathrm{CO}_{2}$ & - & $9 \pm 0.8$ & $181 \pm 10$ \\
\hline $\mathrm{Al}_{3} \mathrm{Gd}$ & - & $6 \pm 0.2$ & $121 \pm 2$ \\
\hline $\mathrm{Al}_{9} \mathrm{CO}_{2}-\mathrm{Al}_{3} \mathrm{Gd}$ & $59.5 \pm 5$ & $6-9$ & $121-181$ \\
\hline According to mixture law & & $4.9-6.78$ & $124-159$ \\
\hline In coarse precipitate & & $5.4 \pm 0.4$ & $146.8 \pm 4.8$ \\
\hline fcc-Al & $23.6 \pm 3$ & $1.3 \pm 0.1$ & $74 \pm 6$ \\
\hline $\mathrm{Al}_{19} \mathrm{Gd}_{3} \mathrm{Ni}_{5}$ & $59.9 \pm 3$ & $5.9 \pm 0.5$ & $185 \pm 4$ \\
\hline $\mathrm{Al}_{9} \mathrm{CO}_{2}$ & - & $9 \pm 0.8$ & $181 \pm 10$ \\
\hline $\mathrm{Al}_{3} \mathrm{Gd}$ & - & $6 \pm 0.2$ & $121 \pm 2$ \\
\hline $\mathrm{Al}_{9} \mathrm{CO}_{2}-\mathrm{Al}_{3} \mathrm{Gd}$ & $16.5 \pm 5$ & $6-9$ & $121-181$ \\
\hline According to mixture law & & $4.83-5.33$ & $148-158$ \\
\hline
\end{tabular}

Nanohardness and Young's modulus in this table are obtained from nanoindentation. Because $\mathrm{Al}_{9} \mathrm{CO}_{2}$ and $\mathrm{Al}_{3} \mathrm{Gd}$ always mix together in the microstructure, to facilitate easier calculation, they are taken as one phase and labeled as $\mathrm{Al}_{9} \mathrm{CO}_{2}-\mathrm{Al}_{3} \mathrm{Gd}$ phase. $\mathrm{Al}_{9} \mathrm{CO}_{2}-\mathrm{Al}_{3} \mathrm{Gd}$ phase then has minimum and maximum values for Young's modulus nanohardness.

\section{Strengthening mechanism}

These high strengths originate from the unique microstructures. As observed in Figures 2 and 3, the present alloys exhibit several unique structural features: (1) nanoscale fcc-Al, which makes the commonly soft fcc-Al very strong owing to the GB strengthening mechanism; (2) a large volume fraction of intermetallic phases, which are much harder than the fcc-Al (see Table 1 and Supplementary Table S2), contributes to the strengthening through a composite effect; (3) the nanoscale dimensions of the intermetallic phases, which make the intermetallics tougher than their coarse counterparts (for example, see Figure 6) while exhibiting high intrinsic strength without premature fracture (see Supplementary Table S2); and (4) the well-bonded phase boundary and/or interfaces, which not only avoid the premature crack initiation and fracture but also, importantly, provide a high confined effect between fcc-Al and intermetallic phases, as illustrated in Figure 5. The negligible solubility of component elements and lack of fine precipitates observed in fcc-Al by TEM observations and STEM-EDX indicate that the Orowan strengthening effect may be weak in these materials.

In the fine precipitate region, two types of phases can be observed: the fcc-Al matrix and the intermetallic phases. The strength of this composite-like microstructure can be described by the rule of mixtures, ${ }^{4}$ which considers the properties of a composite to be the volume-weighted averages of the components' properties and assumes that the components are non-interacting during deformation. If $\sigma_{I M}$ and $\sigma_{A l}$ are defined as the strengths of intermetallics and fcc-Al, respectively, and $f_{I M}$ and $f_{A l}$ are the volume fractions of intermetallics and fcc-Al, respectively, then the strength $\sigma_{y}^{c}$ of the composite due to composite effect can be written as

$$
\sigma_{y}^{c}=f_{A l} \sigma_{A l}+f_{I M} \sigma_{I M} .
$$

This predicts a linear relationship among strengths of all phases and the composite, as illustrated by the straight line drawn in Figure 5a.

In addition to the rule of mixture, the strength of the composite can be further enhanced by the grain refinement of the constituent phases.
The dislocation-dominated GB strengthening is often described by the Hall-Petch relation, ${ }^{4}$ which predicts a dramatic enhancement of strength with decreasing grain size, as illustrated in Figure 5b. In the present alloy, the grain size of the fcc-Al matrix was successfully reduced to $\sim 80 \mathrm{~nm}$, which is near the optimal grain size of $\sim 40 \mathrm{~nm}$ required to achieve the maximum strength. ${ }^{20}$ Furthermore, the dimensions of the intermetallics are on the nanomicron or submicron scale. Investigations of alloys with intermetallic phases showed that the reduction of sample dimensions from bulk to the microscale or nanoscale strongly influence their strengths. ${ }^{21}$ For example, Uchic et al. ${ }^{21}$ found that the $\mathrm{Ni}_{3} \mathrm{Al}-1 \% \mathrm{Ta}$ alloy exhibits $\sim 10$ times higher strength when the sample dimensions decrease to the submicron scale. Here the strengthening effect of the nano-sized intermetallics (Figure 5d) in the present alloys is similar to the strengthening concept in some composites by refining the dimensions of the reinforcing second phases. ${ }^{22}$ For example, the addition of nano-sized particles or carbon nanotubes instead of conventional micrometer-scaled fibers has dramatically enhanced the strength of many $\mathrm{Al}$ matrix composites. ${ }^{23}$ Therefore, by refining the microstructure such as the grains of fcc- $\mathrm{Al}$ and the size of intermetallic phases, the strength of each phase is expected to be greatly enhanced, and the strengths of the composites, depending on the volume fracture of each nano phase, may be estimated by the rule of mixtures (Equation (1)), as plotted by the red line in Figure 5a. The refinement of the microstructure may be a key contributor to the high strength in the present alloy; however, the magnitude of the strength contribution is difficult to measure owing to its structural complexity.

Usually, the strengths of brittle materials such as MGs, NC materials, ceramics and intermetallics are sensitive to confined pressure, ${ }^{24,25}$ and these materials show a tension-compression strength asymmetry and higher hardness values $H$ than those predicted by the equation $H=3 \sigma_{\mathrm{y}}{ }^{26}$ This difference can be understood by analyzing the fracture strength under confining stress states. Using a recently developed fracture criterion for high-strength materials, ${ }^{25}$ we have derived the effective shear yield stress for compressive-type stress states in the form of principal stresses as

$$
\tau_{y}=\sqrt{\left(2+\alpha^{2}\right) \tau_{0}^{2} / 2+\alpha^{2} \sigma_{1} \sigma_{3} / 2} .
$$

where $\sigma_{1}$ and $\sigma_{3}$ are the maximum and minimum principal stresses, respectively; $\tau_{0}$ is the critical shear fracture stress; and $\alpha$ is a material constant (see Supplementary Information S6). Because $\sqrt{\sigma_{1} \sigma_{3}} \leqslant\left(\sigma_{1}+\sigma_{3}\right) / 2$, one can define $\sqrt{\sigma_{1} \sigma_{3}}$ as the confining stress to characterize the magnitude of confinement. For ductile materials with low $\alpha$, the confining pressure has only a small influence. However, Equation (2) indicates that if the confinement is very high, the strength may also be enhanced significantly, which is evidenced by the observed significant increase in strength (up to two orders of magnitude) for iron and tungsten at confining pressures of 200-300 GPa. ${ }^{27}$ Intermetallics are rather brittle and have a relatively large $\alpha$; hence, the confinement is expected to significantly influence the strength of intermetallics. Moreover, strength asymmetry was observed in $\mathrm{NC}$ fcc- $\mathrm{Al},{ }^{20}$ which implied that the strength of fcc-Al could also be affected by the confinement. According to Equation (2), we plotted the influence of the confining stress on strength in Figure $5 c$. Under a high confining stress $\sqrt{\sigma_{1} \sigma_{3}}$, the strengthening induced by the confining effect may be considerable. Because all phases are very strong and the interfaces between them are well bonded, there must be significant inter-confinement among phases, and the effect of confinement on strength is expected to be very important for the present alloys. Because the unique microstructure originates during 

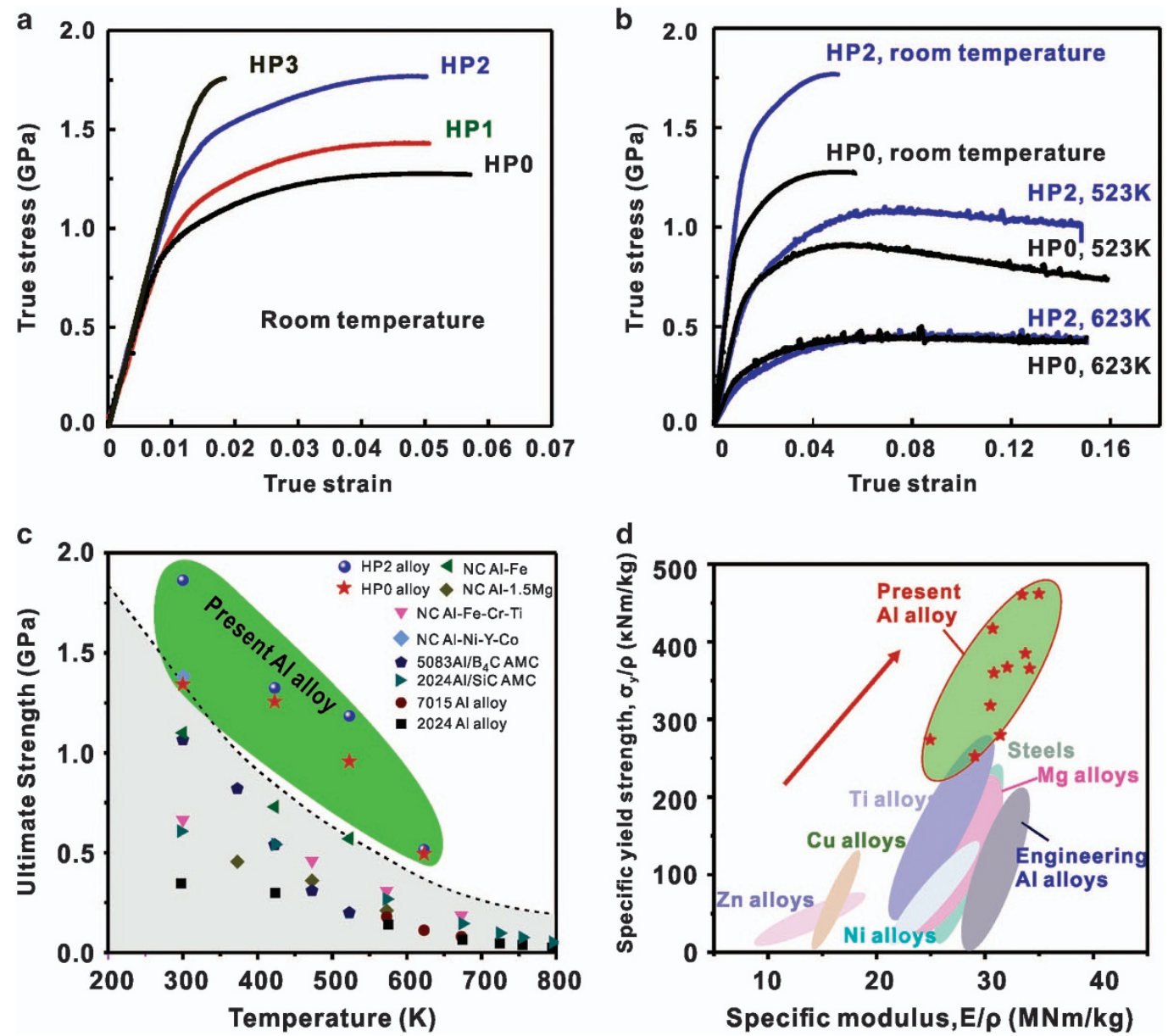

Figure 4 Mechanical properties. (a) Room-temperature true stress-strain curves under uniaxial compression. (b) Compressive true stress-strain curves at elevated temperatures for HPO and HP2. (c) Comparison between the present alloys and other Al alloys with the compressive ultimate strength versus testing temperature. Data for the other materials are taken from the literature. ${ }^{15,31-35}$ (d) Ashby map of specific yield strength versus specific Young's modulus.

material preparation, the high inter-confinement may be introduced during the final hot pressing stage. Upon compressive loading, both the internal and external confinements have key roles in suppressing the premature fracture of brittle phases such as intermetallics and increasing the shear resistance of the $\mathrm{NC} \mathrm{fcc-Al}$, and a higher strength than the value estimated by composite strengthening should eventually be expected. This can be semi-quantitatively elaborated by the following experimental evidence. Because of the limited dimension, it is difficult to directly measure the strength of the individual phases in the present alloys. Instead, dual-phase alloys of $\mathrm{Al}-\mathrm{Al}_{19} \mathrm{Gd}_{3} \mathrm{Ni}_{5}, \quad \mathrm{Al}-\mathrm{Al}_{3} \mathrm{Gd}$ and $\mathrm{Al}-\mathrm{Al}_{9} \mathrm{Co}_{2}$ with microscale phase dimensions were produced, and Vickers hardness and nanoindentation were used to determine their resistance to failure in microscale and nanoscale volumes (Table 1 and Supplementary Table S2). The nanohardness linearly scales with the yield strength of nanoscale pillars $^{28}$ and can thus represent the effect of the nanoscale dimension of the phases on strength. Furthermore, according to the rule of mixture, the composite effect on strength can be estimated based on the measured nanohardness and volume fraction. The calculated nanohardness of the fine precipitate regions in HP2 is in the range of 4.99-6.78 GPa, which is lower than the measured value of $7 \mathrm{GPa}$. Similar results were observed for the coarse precipitate regions (the calculated nanohardness $=4.83-5.33 \mathrm{GPa}$, whereas the measured nanohardness $=5.4 \mathrm{GPa}$ ). Higher hardness values were measured directly with the current material compared with those calculated according to the rule of mixtures, which suggests that the internal confinement among phases must affect the overall strength. This is also corroborated by the smaller difference between the measured and calculated hardness values in the coarse precipitate regions than those in the fine precipitate region because of the weaker confinement. Accordingly, with the effect of confinement, the strength level can be further increased above the estimation based on the composite effect of refined microstructures, as schematically sketched by the blue line in Figure 5.

The internal confinement inside the present alloys could effectively prevent the brittle intermetallics and $\mathrm{NC}$ fcc-Al from premature fracture and thereby provides an opportunity for plastic deformation, which can be verified by the observations of deformation twins in the fcc- $\mathrm{Al}$ and the bending deformation of the intermetallic phases. A high density of stacking faults (SFs) and deformation twins are clearly seen in the fcc-Al in HP2 after room-temperature deformation at a low strain rate of $10^{-3} \mathrm{~s}^{-1}$. These SFs, which have a width of 4-25 atomic planes $(\sim 1-6 \mathrm{~nm})$, lie parallel to the $\{111\}$ planes. Because of the high density of dislocations $\left(1.5-3 \times 10^{16} \mathrm{~m}^{-2}\right)$ and SFs (Supplementary Figure S8), most of the fcc-Al lattice underwent severe lattice distortion. As a result of the severe deformation conditions, the presently observed high density of SFs and twins confirms the existence of high local confined stresses in the fcc-Al phase. The 


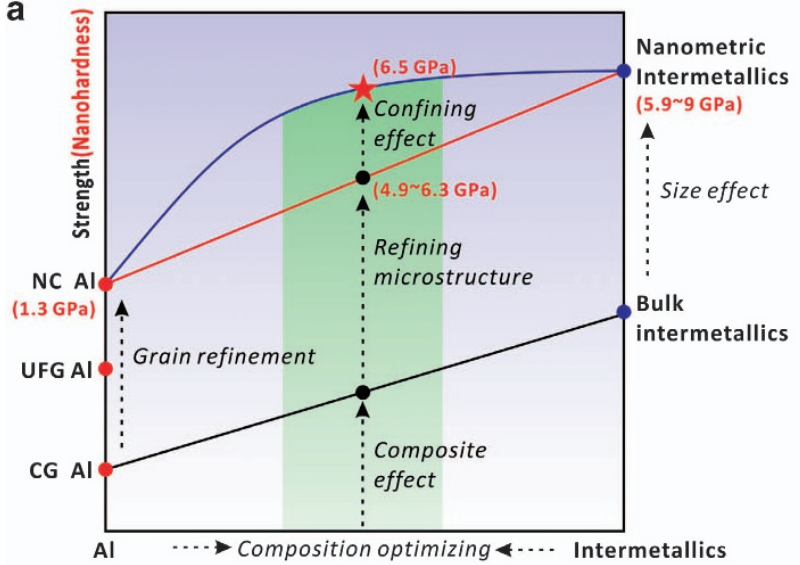

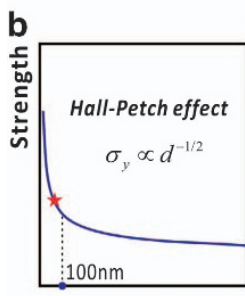

Grain size, $d$

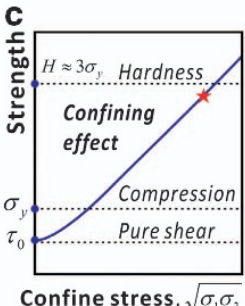

Confine stress, $\sqrt{\sigma_{1} \sigma_{3}}$

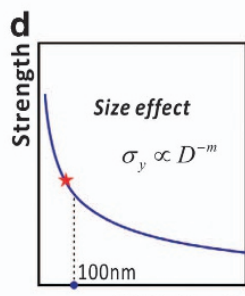

Unit size, $D$
Figure 5 Schematic illustration of the strengthening mechanism. (a) Summary of the strengthening contributions acting in the present $\mathrm{Al}$ alloys. All values in the figure are the nanohardness taken from the bulk samples. (b) GB strengthening of NC fcc-Al. (c) Confining effect of NC fcc-Al on the strength of intermetallics. (d) Size effect for the nanometric intermetallics. Red stars represent the situations corresponding to the present $\mathrm{Al}$ alloys. $\tau_{0}$ is the shear yield stress under pure shear. confined effect and nanoscale dimensions also make the brittle intermetallic phases deformable. In the present alloy, plastic bending of the nanometric $\mathrm{Al}_{19} \mathrm{Gd}_{3} \mathrm{Ni}_{5}$ was observed after compression testing at both room and elevated temperatures, as shown in Figure 6. Angles of $3^{\circ}$ and $8^{\circ}$ between the diffraction patterns of both unbent and bent areas of the same plane can be observed in single-phase $\mathrm{Al}_{19} \mathrm{Gd}_{3} \mathrm{Ni}_{5}$ intermetallics at room temperature (Figure $6 \mathrm{~d}$ ) and elevated temperature (Figure $6 \mathrm{~g}$ ), respectively. The maximum strain on the tensile side of the bent intermetallic rod can be approximated by ${ }^{29}: \varepsilon=d / 2 R_{0}$, where $d$ is the thickness of the intermetallic rod and $R_{0}$ is the curvature radius. According to this equation, the bent strains for $\mathrm{Al}_{19} \mathrm{Gd}_{3} \mathrm{Ni}_{5}$ rods $\mathrm{A}$ and $\mathrm{B}$ displayed in Figure $6 \mathrm{e}$ are $2.8 \%$ and $3.5 \%$, respectively, which indicates that these phases exhibit intrinsic strength rather than the flaw-controlled strength usually observed in bulk and unconfined samples; furthermore, they can suppress the crack initiation and propagation, thereby contributing to the overall strength.

In principle, the confined effect suppresses the tendency for cleavage fracture. Furthermore, the unique hybrid microstructures in these alloys make the crack propagation rather difficult. First, the relatively soft fcc-Al phases are isolated by the intermetallic phases, which thus zigzags the crack propagation pathway along the weakest zones (see Figure 6h). Second, the mechanically bimodal structure of the coarse and fine precipitate regions enhances the resistance to crack propagation by crack-tip blunting, as shown in Figure 6i. It has already been proved that the bimodal structures are beneficial to achieving a combination of good ductility and high strength; ${ }^{30,31}$ the bimodal microstructure may also enhance the mechanical stability of the high-strength alloys in this work.
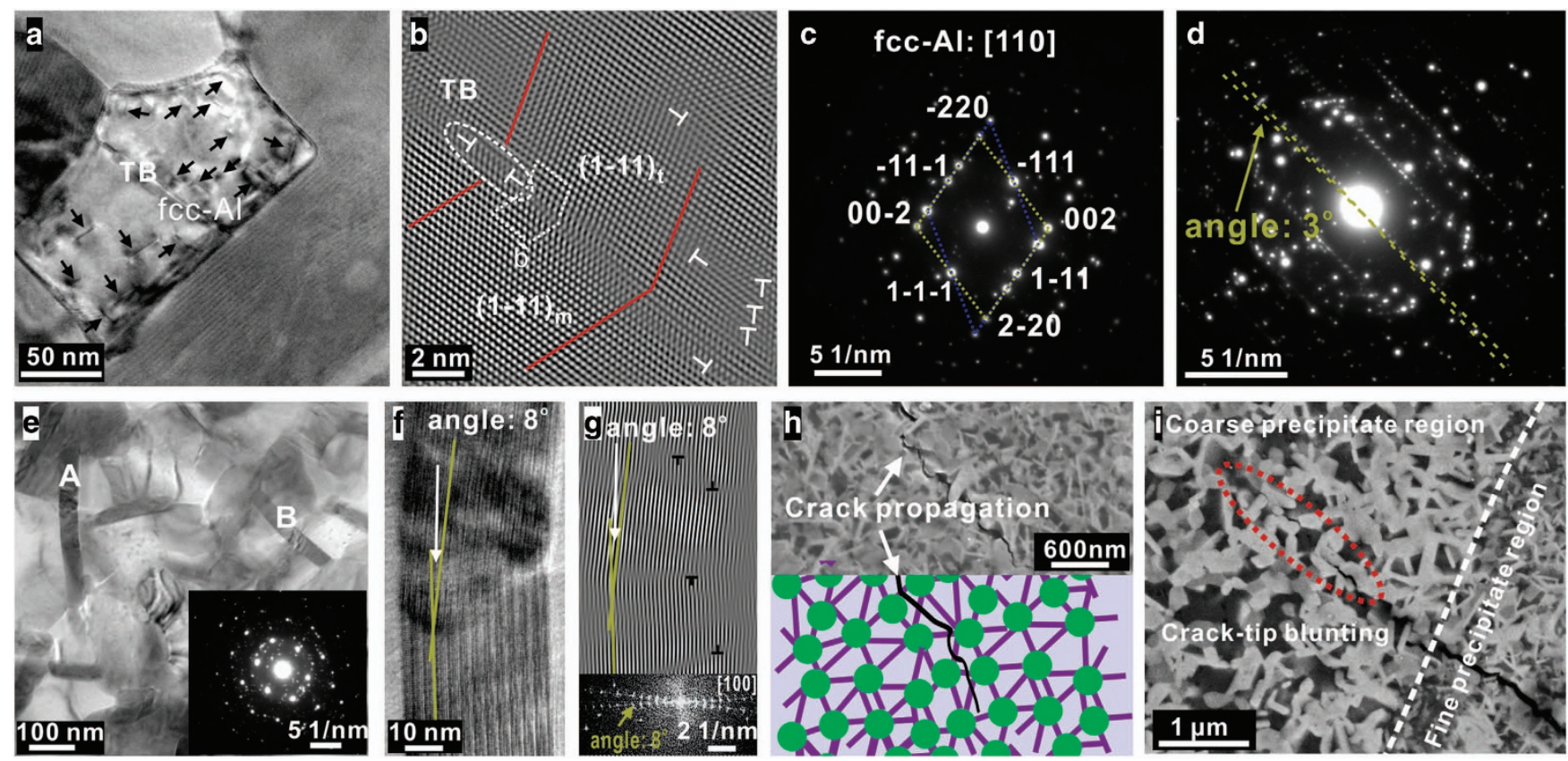

Figure 6 TEM observations of HP2 after compression deformation at room temperature and at $523 \mathrm{~K}$. Compression deformation at room temperature: (a) bright-field TEM image of NC fcc-Al grain surrounded by intermetallics, (b) HRTEM image of NC fcc-Al close to twin boundary (TB) in image (a), (c) selected-area diffraction pattern of the NC fcc-Al grain in image (a), and (d) selected-area diffraction pattern of image (a). (h, i) SEM image of the fractured sample surface after polishing and the schematic illustration of crack propagation. Compression deformation at $523 \mathrm{~K}$ : (e) a bright-field TEM image with a selected-area diffraction pattern in the inset, (f) HRTEM image of the rod-like $\mathrm{Al}_{19} \mathrm{Gd}_{3} \mathrm{Ni}_{5}$ intermetallic labeled as $\mathrm{A}$ in image (e), and (g) a one-dimensional Fourier-filtered image of image (e) with a selected-area diffraction pattern in the inset. 


\section{CONCLUSIONS}

In summary, a microstructural strategy for the production of high-strength Al-based alloys has been developed. The obtained microstructures, which consist of isolated nanoscale fcc-Al and intermetallic compounds, lead to high strength at both room and high temperatures. The basic principles for achieving such high strength are based on the creation of unique hybrid microstructures through the optimization of the processing conditions. The high strength is attributed mainly to the composite structure and the effect of confinement among the nano-sized fcc- $\mathrm{Al}$ and intermetallic phases. It was found that the confining effect could effectively suppress the premature brittle fracture of the intermetallics and the $\mathrm{NC} \mathrm{fcc-Al,} \mathrm{thus}$ offering the possibility to deform plastically and to exhibit intrinsic strength rather than the flaw-controlled strength. The microstructural strategy can, in principle, be applicable to other materials and may thus provide a potential approach to developing high-performance hybrid materials.

\section{CONFLICT OF INTEREST}

The authors declare no conflict of interest.

\section{ACKNOWLEDGEMENTS}

We thank WH Wang, KB Surreddi, P Liu, P Zhang, ZQ Liu, WW Zhang, T Gemming and MS Khoshkhoo for help with experiments and analysis. JE acknowledges financial support by the German Science Foundation under the Leibniz Program (grant EC 111/26-1) and the ERC Advanced Grant INTELHYB (grant ERC-2013-ADG-340025). RTQ and ZFZ acknowledge financial support from the National Natural Science Foundation of China under grant nos. 51331007 and 51301174. This work was also partly supported by the World Premier International Research Center Initiative (WPI), MEXT, Japan.

1 Hirsch, J., Skrotzki, B. \& Gottstein, G. Aluminium Alloys: Their Physical and Mechanical Properties (Wiley-VCH Verlag GmbH, Weinheim, Germany, 2008).

2 Wilm, A. Physikalisch-metallurgische untersuchungen über magnesiumhaltige aluminiumlegierungen. Metall. Z. Gesamte Hüttenkunde 8, 225-227 (1911).

3 Hornbogen, E. Hundred years of precipitation hardening. J. Light Metals 1 127-132 (2001)

4 Meyers, M. A. \& Chawla, K. K. Mechanical Behavior of Materials (Prentice Hall, New Jersey, USA, 1999).

5 Liddicoat, P. V., Liao, X. Z., Zhao, Y., Zhu, Y., Murashkin, M. Y., Lavernia, E. J., Valiev, R. Z. \& Ringer, S. P. Nanostructural hierarchy increases the strength of aluminium alloys. Nat. Commun. 1, 63 (2010).

6 Saito, Y., Tsuji, N., Utsunomiya, H., Sakai, T. \& Hong, R. G. Ultra-fine grained bulk aluminum produced by accumulative roll-bonding (ARB) process. Scripta Mater. 39, 1221-1227 (1998).

7 Valiev, R. Z. \& Langdon, T. G. Principles of equal-channel angular pressing as a processing tool for grain refinement. Prog. Mater. Sci. 51, 881-981 (2006).

8 Zhao, Y. H., Liao, X. Z., Cheng, S., Ma, E. \& Zhu, Y. T. Simultaneously increasing the ductility and strength of nanostructured alloys. Adv. Mater. 18, 2280-2283 (2006).

9 Hayes, R. W., Witkin, D., Zhou, F. \& Lavernia, E. J. Deformation and activation volumes of cryomilled ultrafine-grained aluminum. Acta Mater. 52, 4259-4271 (2004).

10 Youssef, K. M., Scattergood, R. O., Murty, K. L. \& Koch, C. C. Nanocrystalline Al-Mg alloy with ultrahigh strength and good ductility. Scripta Mater. 54, 251-256 (2006).

11 Park, J. M., Pauly, S., Mattern, N., Kim, D. H., Kim, K. B. \& Eckert, J. Microstructura modulations enhance the mechanical properties in $\mathrm{Al}-\mathrm{Cu}-(\mathrm{Si}, \mathrm{Ga})$ ultrafine composites. Adv. Eng. Mater. 12, 1137-1141 (2010).
12 Inoue, A. Amorphous, nanoquasicrystalline and nanocrystalline alloys in Al-based systems. Prog. Mater. Sci. 43, 365-520 (1998).

13 Chookajorn, T., Murdoch, H. A. \& Schuh, C. A. Design of stable nanocrystalline alloys. Science 337, 951-954 (2012).

14 Sasaki, T. T., Ohkubo, T. \& Hono, K. Microstructure and mechanical properties of bulk nanocrystalline Al-Fe alloy processed by mechanical alloying and spark plasma sintering. Acta Mater. 57, 3529-3538 (2009).

15 Kawamura, Y., Mano, H. \& Inoue, A. Nanocrystalline aluminum bulk alloys with a high strength of $1420 \mathrm{MPa}$ produced by the consolidation of amorphous powders. Scripta Mater. 44, 1599-1604 (2001).

16 Kim, K. B., Kim, S. H., Kim, W. T., Kim, D. H. \& Hong, K. T. Structural evolution during heat treatment of mechanically alloyed Al-Cu-Fe-(Si) alloys. Mater. Sci. Eng. A 304-306, 822-829 (2001).

17 Abrosimova, G. E., Aronin, A. S., Barkalov, O. I. \& Dement'eva, M. M. Formation of the nanostructure in amorphous alloys of the Al-Ni-Y system. Phys. Solid State 55, 1773-1778 (2013).

18 Wang, Z., Prashanth, K. G., Scudino, S., He, J., Zhang, W. W., Li, Y., Stoica, M., Vaughan, G., Sordelet, D. \& Eckert, J. Effect of ball milling on structure and thermal stability of $\mathrm{Al}_{84} \mathrm{Gd}_{6} \mathrm{Ni}_{7} \mathrm{CO}_{3}$ glassy powders. Intermetallics 46, 97-102 (2014).

19 Ashby, M. F. Materials Selection in Mechanical Design. 3rd edn (ButterworthHeinemann, Berlin, Germany, 2005).

20 Cheng, S., Spencer, J. A. \& Milligan, W. W. Strength and tension/compression asymmetry in nanostructured and ultrafine-grain metals. Acta Mater. 51, 4505-4518 (2003).

21 Uchic, M. D., Dimiduk, D. M., Florando, J. N. \& Nix, W. D. Sample dimensions influence strength and crystal plasticity. Science 305, 986-989 (2004).

22 Lloyd, D. J. Particle reinforced aluminium and magnesium matrix composites. Int Mater. Rev. 39, 1-23 (1994).

23 Bakshi, S. R., Lahiri, D. \& Agarwal, A. Carbon nanotube reinforced metal matrix composites - a review. Int. Mater. Rev. 55, 41-64 (2010).

24 Pippan, R., Wetscher, F., Hafok, M., Vorhauer, A. \& Sabirov, I. The limits of refinement by severe plastic deformation. Adv. Eng. Mater. 8, 1046-1056 (2006).

25 Qu, R. T. \& Zhang, Z. F. A universal fracture criterion for high-strength materials. Sci. Rep. 3, 1117 (2013).

26 Zhang, P., Li, S. X. \& Zhang, Z. F. General relationship between strength and hardness. Mater. Sci. Eng. A 529, 62-73 (2011).

27 Hemley, R. J. X-ray imaging of stress and strain of diamond, iron, and tungsten at megabar pressures. Science 276, 1242-1245 (1997).

28 Greer, J. R. \& De Hosson, J. T. M. Plasticity in small-sized metallic systems: intrinsic versus extrinsic size effect. Prog. Mater. Sci. 56, 654-724 (2011).

29 Aljerf, M., Georgarakis, K. \& Yavari, A. R. Shaping of metallic glasses by stress-annealing without thermal embrittlement. Acta Mater. 59, 3817-3824 (2011).

30 Wu, X., Jiang, P., Chen, L., Yuan, F. \& Zhu, Y. T. Extraordinary strain hardening by gradient structure. Proc. Natl Acad. Sci. USA 111, 7197-7201 (2014).

31 Sawangrat, C., Kato, S., Orlov, D. \& Ameyama, K. Harmonic-structured copper: performance and proof of fabrication concept based on severe plastic deformation of powders. J. Mater. Sci 49, 6579-6585 (2014).

32 Zhang, X. N., Geng, L. \& Xu, B. Compressive behaviour of Al-based hybrid composites reinforced with SiC whiskers and SiC nanoparticles. Mater. Chem. Phys. 101, 242-246 (2007).

33 Jin, N., Zhang, H., Han, Y. Wu, W. \& Chen, J. Hot deformation behavior of 7150 aluminum alloy during compression at elevated temperature. Mater. Charact. 60, 530-536 (2009).

34 Shaw, L., Luo, H., Villegas, J. \& Miracle, D. Compressive behavior of an extruded nanocrystalline Al-Fe-Cr-Ti alloy. Scripta Mater. 50, 921-925 (2004).

35 Inoue, A. \& Kimura, H. High elevated-temperature strength of Al-based nanoquasicrystalline alloys. Nanostruct. Mater. 11, 221-231 (1999).

This work is licensed under a Creative Commons Attribution 4.0 International License. The images or other third party material in this article are included in the article's Creative Commons license, unless indicated otherwise in the credit line; if the material is not included under the Creative Commons license, users will need to obtain permission from the license holder to reproduce the material. To view a copy of this license, visit http:// creativecommons.org/licenses/by/4.0/

Supplementary Information accompanies the paper on the NPG Asia Materials website (http://www.nature.com/am) 